\title{
Pembuatan dan Pengujian Sifat Mekanik Plastik Biodegradable Berbasis Tepung Biji Durian
}

\section{Manufacture and Testing of Mechanical Properties on Durian Seed Flour based Biodegradable Plastics}

\author{
Dewi Arini*), M.Syahrul Ulum dan Kasman \\ Jurusan Fisika Fakultas MIPA Universitas Tadulako
}

\begin{abstract}
The manufacture and testing of mechanical properties on durian seed flour based biodegradable plastics have been done. The purpose of this research is to know the mechanical properties of the biodegradable plastics including the tensile strength test, elongation, and modulus Young. The tensile strength test is done by using Stress Analyzer 1000 tool, with a specimen shape which refers to the ASTM-D638 standard. Based on the results of the research, the mechanical properties of the biodegradable plastics obtained are an average value of tensile strength $0,1158 \mathrm{MPa}$, elongation 2,1875\%, and modulus Young 4,1515 MPa. Compared to the moderate properties of biodegradable plastic type, the value are still far from the standard. This indicates that the method used in manufacturing the biodegradable plastics in this research still needs to be optimized.
\end{abstract}

Keywords: Biodegradable plastic, Durian seed, Mechanical properties.

\begin{abstract}
ABSTRAK
Pembuatan dan pengujian sifat mekanik plastik biodegradable berbasis tepung biji durian telah dilakukan. Penelitian ini bertujuan untuk mengetahui sifat mekanik plastik biodegradable yang meliputi uji kuat tarik, elongasi, dan modulus Young. Pengujian sifat mekanik kuat tarik dilakukan menggunakan alat Stress Analyzer 1000, dengan bentuk spesimen uji tarik yang merujuk pada standar ASTM-D638. Berdasarkan hasil penelitian, diperoleh nilai kuat tarik rata-rata $0,1158 \mathrm{MPa}$, elongasi $2,1875 \%$, dan modulus Young 4,1515 MPa. Dibandingkan dengan golongan moderate properties plastik biodegradable, nilai tersebut masih jauh dari standar. Hal ini menunjukkan bahwa metode yang digunakan dalam pembuatan plastik biodegradable pada penelitian ini masih perlu dioptimalkan.
\end{abstract}

Kata Kunci: Plastik biodegradable, Biji durian, Sifat mekanik 


\section{LATAR BELAKANG}

Plastik merupakan bahan kemasan pangan yang paling populer digunakan. Plastik banyak digunakan di berbagai sektor kehidupan. Hampir setiap produk industri menggunakan plastik sebagai kemasan atau sebagai bahan dasar. Setiap tahun sekitar 100 juta ton plastik diproduksi dunia untuk digunakan di berbagai sektor industri dan sekitar itulah limbah plastik yang dihasilkan setiap tahun (Martaningtyas, 2004).

Limbah plastik tidak dapat terurai secara alami di dalam tanah sehingga terjadi penumpukan limbah plastik yang menyebabkan pencemaran dan kerusakan lingkungan. Salah satu solusi untuk mengurangi pencemaran limbah plastik adalah mengganti bahan dasar plastik konvensional menjadi bahan yang mudah terurai seperti pati (Huda dkk., 2007). Pati merupakan bagian dari karbohidrat, pati adalah bahan utama yang dihasilkan oleh tumbuhan untuk menyimpan kelebihan glukosa. Komposisi pati pada umumnya terdiri dari sebagian besar amilopektin dan sisanya amilosa (Hartati, 2003).

Salah satu sumber pati yaitu biji durian. Biji durian memiliki kandungan pati sebesar 42,1\% (Afif, 2009). Kandungan pati biji durian yang cukup tinggi ini memungkinkan digunakan sebagai bahan dasar pembuatan plastik biodegradable.
Selain memiliki kandungan pati yang cukup tinggi, biji durian banyak terdapat di Sulawesi Tengah dan belum termanfaatkan secara maksimal.

Nathiqoh (2013) telah melakukan penelitian tentang pembuatan dan karakterisasi plastik biodegradable berbasis tepung biji durian. Karakterisasi yang dilakukan meliputi pengukuran ketahanannya terhadap air, densitas, uji transparansi, dan lama waktu degradasi yang diperlukan.

Karakterisasi yang telah dilakukan belum mencakup karakterisasi sifat mekanik dari plastik biodegradable yang telah dihasilkan dalam penelitian tersebut. Karena pentingnya sifat mekanik suatu bahan, maka perlu dilakukan penelitian lanjutan tentang sifat mekanik plastik biodegradable yang terbuat dari tepung biji durian, yang meliputi uji kuat tarik, elongasi, dan modulus Young.

\section{BAHAN DAN METODE}

Bahan yang digunakan pada penelitian ini yaitu biji durian, aquades, khitosan, asam asetat $0,1 \%$, gliserol, dan air kapur. Proses pembuatan plastik biodegradable yang dihasilkan pada penelitian ini, yaitu dengan cara isolasi pati biji durian, pembuatan sediaan larutan, pencampuran bahan dasar, dan pencetakan.

Pembuatan sediaan larutan dengan melarutkan $3 \mathrm{ml}$ kitosan dalam $300 \mathrm{ml}$ 
asam asetat $0,1 \%$ dan $5 \mathrm{ml}$ pati ke dalam 50 $\mathrm{ml}$ aquades. Pencampuran bahan dilakukan dengan komposisi larutan kitosan $3 \mathrm{ml}$,

gliserol $0,2 \mathrm{ml}$, pati $5 \mathrm{ml}$, dan aquades 50 ml. Bahan dicampur dan dipanaskan sampai pada suhu $85^{\circ} \mathrm{C}$. Kemudian dituangkan ke dalam cetakan, dikeringkan dalam oven pada suhu $45^{\circ} \mathrm{C}$, dan didinginkan pada suhu $23^{\circ} \mathrm{C}$.

Pengujian sifat mekanik menggunakan alat uji tarik Stress Analyzer 1000, dan untuk memperoleh nilai kuat tarik, elongasi, dan modulus young, diperoleh menggunakan persamaan sebagai berikut:

$$
\begin{array}{ll}
\sigma=\frac{F}{A} & 1 \\
\epsilon=\frac{l-l o}{l o} \times 100 \% & 2 \\
\mathrm{E}=\frac{\sigma}{\epsilon} & 3
\end{array}
$$

\section{HASIL DAN PEMBAHASAN}

Pembuatan plastik biodegradable berbasis tepung biji durian pada penelitian ini telah dilakukan dan diperoleh plastik biodegradable berupa lembaran plastik seperti terlihat pada Gambar 1. Lembaran plastik tersebut berwarna kecoklatan dengan ketebalan 0,07 $\mathrm{mm}$ dan massa jenis $1,42 \mathrm{gr} / \mathrm{cm}^{3}$.Pengujian sifat mekanik plastik dilakukan dengan bantuan alat stress analyzer 1000 dengan mengikuti standar ASTM-D638 (Susilawati, 2011). Informasi yang diperoleh dari stress analysis tersebut adalah gaya tarik maksimum pada saat spesimen putus.

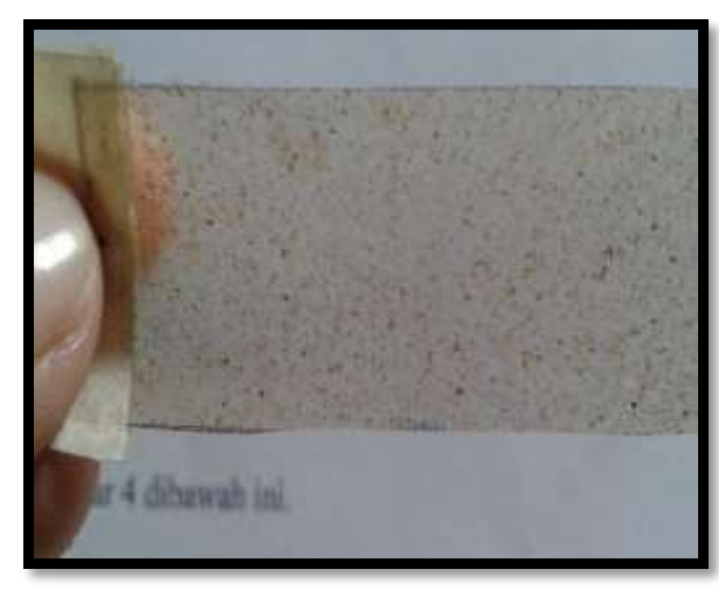

Gambar 1. Plastik biodegradable berbasis tepung biji durian (Durio Zibethinus Murr)

Hasil pengujian dan perhitungan menggunakan persamaan 1, 2 dan persamaan 3. Sifat mekanik plastik yang meliputi nilai kuat tarik, elongasi, dan modulus Young secara lengkap disajikan pada Tabel 1.

Tabel 1. Nilai sifat mekanik plastik biodegradable berbasis tepung biji durian.

\begin{tabular}{cccc}
\hline $\begin{array}{c}\text { Sam } \\
\text { pel }\end{array}$ & $\begin{array}{c}\text { Kuat } \\
\text { tarik } \\
(\mathrm{MPa})\end{array}$ & $\begin{array}{c}\text { Elongasi } \\
(\%)\end{array}$ & $\begin{array}{c}\text { Modulus } \\
\text { Young } \\
(\mathrm{MPa})\end{array}$ \\
\hline $\mathrm{A}$ & 0,3128 & 3,125 & 10,008 \\
$\mathrm{~B}$ & 0,02317 & 1,563 & 1,483 \\
$\mathrm{C}$ & 0,02317 & 1,563 & 1,483 \\
$\mathrm{D}$ & 0,02317 & 1,563 & 1,483 \\
$\mathrm{E}$ & 0,1969 & 3,125 & 6,301 \\
\hline Rata & 0,1158 & 2,188 & 4,152 \\
\hline
\end{tabular}

Berdasarkan Tabel 1, terlihat bahwa nilai sifat mekanik yang meliputi nilai kuat tarik, elongasi, dan modulus Young plastik biodegradable berbasis tepung biji durian yang dihasilkan pada penelitian ini, 
masing-masing memiliki nilai sifat mekanik yang berbeda-beda walaupun dengan perlakuan yang sama. Hal ini kemungkinan disebabkan karena homogenitas plastik yang dihasilkan berbeda-beda, karena perlakuan pengadukan dilakukan secara manual yang hanya mengggunakan batang pengaduk. Ketebalan plastik yang dihasilkan juga tidak merata sehingga mempengaruhi nilai sifat mekanik.

\section{Kuat Tarik}

Kuat tarik merupakan tegangan maksimum yang dapat ditahan oleh material sebelum terputus. Pada Tabel 1 dapat dilihat nilai rata-rata kuat tarik plastik yang dihasilkan yaitu $0,1158 \mathrm{MPa}$. Bila dibandingkan dengan nilai kuat tarik golongan moderate properties (standarisasi plastik biodegradable) untuk nilai kuat tarik yaitu 1-10 MPa (Purwanti, 2010), maka plastik yang diperoleh memiliki nilai kuat tarik yang masih relatif rendah. Beberapa faktor yang mempengaruhi rendahnya nilai kuat tarik plastik yang dihasilkan yaitu sebagai berikut:

a. Konsentrasi kitosan

Kitosan merupakan bahan tambahan pada pembuatan plastik biodegradable yang berfungsi untuk memperbaiki transparansi plastik yang dihasilkan (Joseph et all., 2009). Selain itu kitosan juga mempengaruhi nilai kuat tarik dari plastik biodegradable. Semakin banyak penggunaan konsentrasi kitosan, maka semakin meningkat nilai kuat tarik plastik yang dihasilkan (Coniwanti dkk., 2014).

Menurut penelitian yang telah dilakukan oleh Coniwanti dkk. (2014) penggunaan konsentrasi kitosan 29,4\% menghasilkan kuat tarik 2,1 MPa.Konsentrasi kitosan yang digunakan pada

penelitian ini yaitu $5,16 \%$. Jika dibandingkan dengan konsentrasi kitosan yang digunakan oleh Coniwanti dkk. (2014) maka konsentrasi tersebut terbilang rendah. Hal ini mungkin menjadi salah satu faktor rendahnya nilai kuat tarik plastik yang dihasilkan. Oleh karena itu penggunaan konsentrasi kitosan perlu dioptimalkan.

b. Konsentrasi pati

Bahan utama dalam pembuatan plastik yang berfungsi agar plastik yang dihasilkan mampu terdegradasi oleh alam menjadi senyawa yang ramah lingkungan adalah pati (Darni dkk., 2010).

Kemampuan biodegradasi disebabkan karena akibat proses hidrolisis pati oleh mikroorganisme. Akan tetapi, semakin banyak jumlah pati yang ditambahkan maka semakin kecil nilai kuat tarik yang dihasilkan (Inggaweni dan Suyatno,2015). 
Penggunaan konsentrasi pati $90 \%$ menghasilkan nilai kuat tarik plastik 5,43 MPa (Saputra dkk., 2015). Konsentrasi pati yang digunakan pada penelitian ini yaitu 94,50\%. Berdasarkan konsentrasi tersebut, konsentrasi pati yang digunakan pada penelitian ini lebih tinggi dibandingkan dengan penggunaan konsentrasi pati yang digunakan oleh Saputra dkk. (2015), sehingga menyebabkan rendahnya nilai kuat tarik plastik yang dihasilkan.

c. Konsentrasi gliserol

Gliserol merupakan bahan plasticizer.

Penggunaan gliserol pada pembuatan plastik bertujuan untuk menurunkan sifat kaku dari pati (Inggaweni dan Suyatno, 2015). Gliserol memberikan suatu sifat yang lembut dan fleksibel pada plastik biodegradable (Purbasari dkk., 2014).

Pada tahun 2015, Apriyani dkk., telah melakukan penelitian tentang pengaruh konsentrasi gliserol terhadap sifat mekanik plastik biodegradable. Apriyani dkk. (2015) menentukan bahwa konsentrasi optimum gliserol untuk memperoleh plastik biodegradable dengan kuat tarik yang tinggi adalah $0,6 \%$. Pada penelitian ini penggunaan konsentrasi gliserol 0,34\%. Konsentrasi tersebut berada dibawah konsentrasi optimum, sehingga nilai kuat tarik plastik yang dihasilkan rendah.

d. Homogenitas plastik

Kuat tarik suatu plastik biodegradable dipengaruhi oleh homogenitas plastik tersebut. Semakin seragam komponen penyusunnya maka akan menghasilkan lapisan yang homogen dan rapat (Dias et al., 2010). Semakin tinggi homogenitas, semakin tinggi kuat tarik plastik yang dihasilkan (Coniwanti dkk., 2014).

Homogenitas lapisan plastik yang dihasilkan kurang homogen. Hal ini juga mungkin menyebabkan plastik yang dihasilkan memiliki nilai kuat tarik yang masih rendah, sehingga tidak memenuhi golongan moderate properties.

\section{Elongasi}

Elongasi merupakan perubahan panjang maksimum film sebelum terputus. Pengujian elongasi dilakukan dengan membandingkan penambahan panjang yang terjadi dengan panjang bahan sebelum dilakukan uji tarik. Penentuan elongasi dilakukan dengan menggunakan persamaan 2. Pada Tabel 1 dapat dilihat nilai rata-rata elongasi plastik yang dihasilkan yaitu $2,1875 \%$. Bila dibandingkan dengan nilai kuat tarik plastik yang memenuhi golongan moderate properties untuk nilai elongasi yaitu 10-20\% (Purwanti, 2010), maka plastik yang diperoleh memiliki nilai elongasi yang rendah. Beberapa faktor yang 
mempengaruhi rendahnya nilai elongasi plastik yang dihasilkan yaitu sebagai berikut:

a. Konsentrasi kitosan

Kitosan dalam pembuatan plastik biodegradable juga berfungsi sebagai penguat, sehingga mempengaruhi nilai elongasi dari plastik biodegradable. Akan tetapi, semakin banyak kitosan yang ditambahkan, maka elongasi plastik yang dihasilkan akan semakin menurun (Coniwanti dkk., 2014).

Coniwanti dkk. (2014) telah melakukan penelitian dengan penggunaan konsentrasi kitosan 8,3\% dan menghasilkan nilai elongasi plastik yaitu 19\%. Penelitian ini menggunakan konsentrasi kitosan 29,4\%. Penggunaan konsentrasi kitosan yang digunakan pada penelitian ini lebih tinggi dibandingkan dengan penelitian yang telah dilakukan oleh Coniwanti dkk. (2014), sehingga nilai elongasi plastik yang dihasilkan masih relatif rendah.

b. Konsentrasi pati

Pati merupakan polisakarida yang digunakan sebagai bahan utama pembuatan plastik biodegradable yang juga berfungsi sebagai pengikat ikatan polimer. Pati mempengaruhi nilai elongasi

plastik. Semakin banyak pati yang ditambahkanmaka plastik yang dihasilkan semakin kaku yang menyebabkan elongasi semakin menurun (Saputra dkk., 2015).

Saputra dkk. (2015) telah melakukan penelitian dengan penggunaan konsentrasi pati $90 \%$ dan diperoleh nilai elongasi yaitu

$30 \%$. Konsentrasi yang digunakan pada penelitian ini lebih tinggi yaitu 94,50\% Hal ini yang menyebabkan rendahnya nilai elongasi plastik yang dihasilkan.

c. Konsentrasi gliserol

Plasticizer adalah cairan yang mempunyai titik didih tinggi, sehingga ketika dicampurkan dengan suatu polimer akan memberikan suatu sifat yang lembut dan fleksibel. Semakin tinggi kadar konsentrasi gliserol yang digunakan semakin tinggi elongasi dari bioplastik tersebut (Purbasari dkk., 2014).

Menurut penelitian yang telah dilakukan oleh Purbasari dkk. (2015) penggunaan konsentrasi gliserol 50\% diperoleh nilai elongasi yaitu $46 \%$. Penggunaan konsentrasi gliserol yang digunakan pada penelitian ini yaitu $0,34 \%$. Jika dibandingkan dengan konsentrasi gliserol yang digunakan oleh Purbasari dkk. (2015) maka konsentrasi tersebut jauh lebih rendah. Hal ini yang menyebabkan rendahnya nilai elongasi plastik yang dihasilkan.

\section{Modulus Young}


Modulus Young dilakukan untuk mengetahui ukuran kekakuan bahan yang dihasilkan. Modulus Young diperoleh dari perbandingan antara kekuatan tarik terhadap elongasi (persen pemanjangan). Penentuan modulus Young dapat diketahui dengan menggunakan persamaan 3. Pada Tabel 1 dapat dilihat nilai rata-rata modulus Young

plastik yang dihasilkan yaitu 4,1515 MPa.

Menurut penelitian yang telah dilakukan oleh Setiani dkk. (2013), nilai modulus Young plastik biodegradable yang dihasilkan yaitu 2,72 $\mathrm{MPa}$ yang berarti plastik tersebut kaku. Jika dibandingkan dengan nilai modulus Young plastik yang dihasilkan pada penelitian ini, maka plastik biodegradable yang dihasilkan masih tergolong kaku.

\section{KESIMPULAN}

Karakterisasi plastik biodegradable berbasis tepung biji durian yang dibuat dengan metode pada penelitian ini menunjukkan nilai kuat tarik rata-rata 0,1158 MPa, elongasi 2,1875\%, dan modulus Young 4,1515 MPa.Dibandingkan dengan golongan moderate properties plastik biodegradable, nilai tersebut masih jauh dari standar. Hal ini menunjukkan bahwa metode yang digunakan dalam pembuatan plastik biodegradable pada penelitian ini masih perlu dioptimalkan.

\section{UCAPAN TERIMA KASIH}

Ucapan terimakasih kepada Kepala Laboratorium dan Laboran Lab. Agrotekhnologi Fakultas Pertanian UNTAD dan Kepala Laboratorium, Laboran, dan Asisten Lab. Uji Bahan Teknik Mesin Fakultas Teknik UNTAD.

\section{DAFTAR PUSTAKA}

Afif, M. (2009). Pembuatan Jenang dengan Tepung Biji Durian (Durio zibethinus murr). Skripsi. Fakultas Teknik, Universitas Negeri Semarang. Semarang.

Apriyani, M., dan Sedyadi E. (2015). Sintesis Karakterisasi Plastik Biodegradable dari Pati Onggong singkong dan Ekstrak Lidah Buaya (Aloe vera) dengan Plasticizer Gliserol. Jurnal Sains Dasar, 4(2), 145-152.

Coniwanti, P., Laila, L., dan Alfira, M, R. (2014). Pembuatan Film Plastik Biodegradable dari Pati Jagung dengan Penambahan Kitosan dan Pemlastis Gliserol. Jurnal Tekhnik Kimia, 20(4), 22-30.

Darni, Y., dan Utami, H. (2010). Studi Pembuatan dan Karakteristik Sifat Mekanik dan Hidrofobisitas Bioplastik dari Pati Sorgum. Jurnal Rekayasa Kimia dan Lingkungan, 7(4), 88-93.

Dias, A. B., Müller, C.M.O., Larotonda, F.D.S., and Laurindo, J. B. (2010), Biodegradable Films Based on Rice Starch and Rice Flour, Journal of Cereal Science, 51, pp. 213-219.

Hartati,S .(2003). Analisis Kadar Pati dan Serat Kasar Tepung beberapa Kultivar Talas (ColocasiaesculentaL.Schott), Jurnal Natur Indonesia, 6:29-33.

Huda,Thorikul, dan Firdaus, F. (2007). Karakteristik Fisikokimiawi Film 
Plastik Biodegradable dari Komposit Pati Singkong-Ubi Jalar, 4(2).

Inggaweni, L., dan Suyatno. (2015). Karakteristik Sifat Mekanik Plastik Biodegradable Dari Komposit High Density Polyethylene Dan Pati Kulit Singkong. Prosiding Seminar Nasional Kimia. ISBN: 978-6020951-058.

Joseph, C.S., Harish Prashanth, K. V., Rastogi, N.K., Indiramma, A. R., Yella, S.R., and Raghhavarao, S. (2009). Optimum Blend of Chitosan and Poly for Fabrication of Film for Food Packaging Aplications. Jurnal Of Food Bioprocess Technology, 4: 1179-1185.

Martaningtyas, D. (2004). Potensi Plastik Biodegradable, http://www.pikiran rakyat.com/cetak/0904/02/cakrawal a/lainnya06.htm. Diakses 4 November 2016.

Nathiqoh. (2013). Uji ketahanan biodegradable plastic berbasis tepung biji durian (Durio zibethinus murr) terhadap air dan pengukuran densitasnya. Skripsi. Universitas Negeri Semarang, Semarang.

Purbasari, A., Ariani, F, E., dan Mediani, K, R. (2014). Bioplastik Dari Tepug Dan Pati Biji Nangka. Jurnal Teknik Kimia. ISBN 978-602-99334-3-7, 54-59.

Purwanti, A. (2010). Analisis Kuat Tarik dan Elongasi Plastik Kitosan Terplastisasi Sorbitol. Jurnal Teknologi, 3(2), 99-106.

Saputra, A., Lutfi M dan Masruroh, E. (2015). Studi Pembuatan Karakteristik Sifat Mekanik Plastik Biodegradable Berbahan Dasar Ubi Suweg (Amorphophallus campanulatus). Jurnal Keteknikan Pertanian Tropis dan Biosistem, 3 (1), 1-6.

Setiani, W., Sudiarti, T., dan Rahmidar, L. (2013). Preparasi Dan Karakterisasi
Edible Film Dari Pati Poliblend Pati Sukun-Kitosan. Jurnal Kimia Valensi, 3(2), 100-109.

Susilawati, Mustafa, I., dan Maulina, D. (2011). Biodegradable Plastics from A Mixture of Low Density Polyethilene (LDPE) and Cassava Starch with the Addition of Acrylic ACID. Jurnal Natural, 11(2), 69-73. 